\title{
TESTING AND CHARACTERIZATION OF CMC COMBUSTOR LINERS
}

\author{
R. Craig Robinson
}

QSS Group, Inc., NASA Glenn Research Center, Cleveland, OH 44135

Michael J. Verrilli

NASA Glenn Research Center, Cleveland, OH 44135

\begin{abstract}
Multiple combustor liner applications, both segmented and fully annular designs, have been configured for exposure in NASA's High Pressure Burner Rig (HPBR). The segmented liners were attached to the rig structure with $\mathrm{SiC} / \mathrm{SiC}$ fasteners and exposed to simulated gas turbine conditions for nearly 200 hours. Test conditions included pressures of 6 atm. gas velocity of $42 \mathrm{~m} / \mathrm{s}$, and gas temperatures near $1450^{\circ} \mathrm{C}$. The temperatures of both the cooled and combustionflow sides of the liners were measured using optical and contact measurement techniques. Minor weight loss was observed, but the liners remained structurally sound, although damage was noted in some fasteners.
\end{abstract}

\section{INTRODUCTION}

The use of ceramic matrix composites (CMCs) as combustor liners has the potential to improve gas turbine engine performance, through lower emissions and higher cycle efficiency, relative to today's superalloy hot section components. Evaluation of CMC components and sub-component features under gas turbine conditions is paramount in demonstrating the capabilities of these material systems in the complex thermal stress and environmentally aggressive engine environment. To date, only limited testing has been conducted on CMC combustor concepts and subelements of this type throughout the industrye. The combustion environment of the HPBR is an outstanding simulation of the turbine engine that economically deliver the gas compositions at pressures, gas velocities and temperatures required for additional exposure of such research materials.

\section{BACKGROUND}

Under the High Speed Research/Enabling Propulsion Materials (HSR/EPM) Program, the Rich-burn, Quick-quench, Lean-burn (RQL) Sector Rig was 


\section{$1 e^{2}$ a}

developed at NASA GRC to demonstrate the structural durability of SiC/SiC liners in a combustion environment. Designed by Pratt \& Whitney, the RQL sector rig contained two rich zone liner cans that transitioned to a lean zone. Six different $\mathrm{SiC} / \mathrm{SiC}$ components made up the combustion chamber ${ }^{4}$ including the lean transition liners (LTLs) being discussed in this paper. The LTLs are curved plates, measuring approx $5.1 \mathrm{~cm} \mathrm{x}, 3.3 \mathrm{~cm}$, covering a $60^{\circ}$ arc of a $10.2 \mathrm{~cm}$ inner diameter, Two built-up regions of 12-ply thicknessireinforce the locations of the attachment holes, with 6-ply thickness in the remaining areas. The LTLs are fastened to the rig's metal back structure with $\mathrm{SiC} / \mathrm{SiC}$ Miller attachments ${ }^{5}$ as

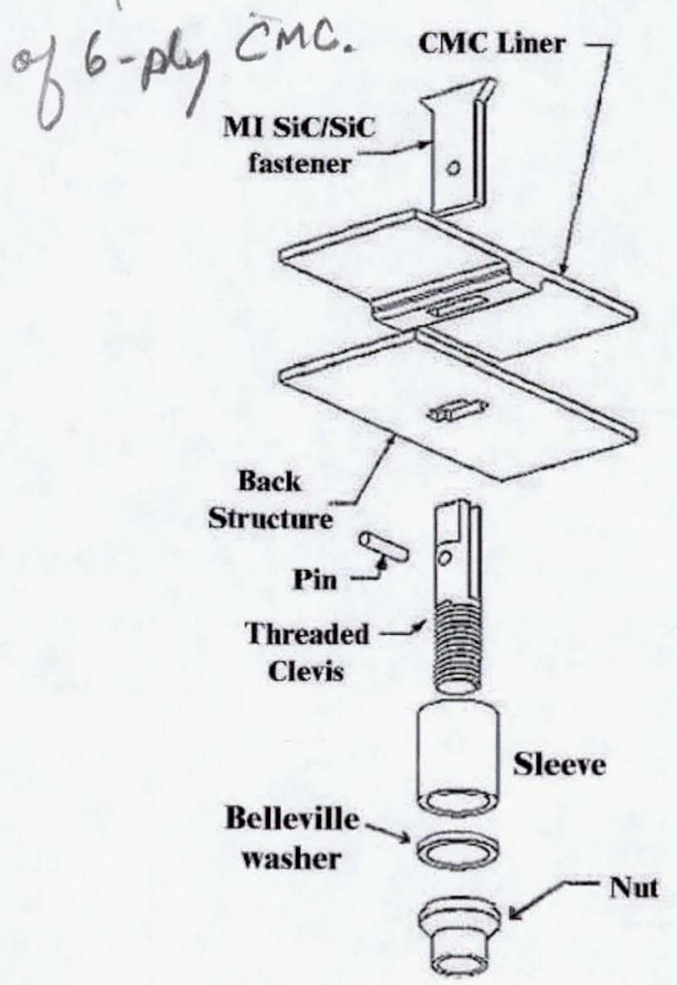
illustrated in Figure 1.

Testing of LTLs under the EPM Program ${ }^{6-7}$ was limited due to operational and cost issues. Under the Efficient Engine Technology (UEET) Program, the HPBR was selected to continue certain sub-component feature and component level testing because of it's versatility in test fixturing and design. In the current effort the geometry of the LTL liners, their CMC attachments, and the HPBR configuration was adapted to accommodate continued testing.

Figure 1-CMC panels fastened to metallic back structure using Miller attachment scheme.

\section{MATERIAL}

The combustor liners were manufactured by Honeywell Advanced Composites from a $\mathrm{SiC} / \mathrm{SiC}$ developed under the/EPM Program. A slurry-cast, melt infiltrated $\mathrm{SiC}$ matrix was reinforced with Sylramic $^{\mathrm{TM}} \mathrm{SiC}$ fibers. The fiber tows were woven into a 5-harness satin weave cloth using fiber tow spacings of 18 and 22 ends per inch, resulting in a nominal fiber volume fractions of $35 \%$ and $42 \%$, respectively.

\section{EXPERIMENTAL PROCEDURES}

The High Pressure Burner Rig ${ }^{8}$ at NASA Glenn Researeh Center is a highvelocity, pressurized combustion test rig used for high-temperature environmental durability studies of advanced materials and components. The facility, shown in Figure 2, burns jet fuel and air in controlled ratios, simulating combustion gas chemistries, temperatures, pressures, and gas velocities representative of today's gas turbine engines. Operating conditions include $1.0 \mathrm{~kg} / \mathrm{sec}$ combustion and secondary cooling airflow capability, equivalence ratios of $0.5-1.0$ with typically $10 \% \mathrm{H}_{2} \mathrm{O}$ vapor pressure, gas temperatures ranging $700-1650^{\circ} \mathrm{C}$, test pressures ranging 4-12 atmospheres, and gas velocities ranging $10-30 \mathrm{~m} / \mathrm{s}$. 


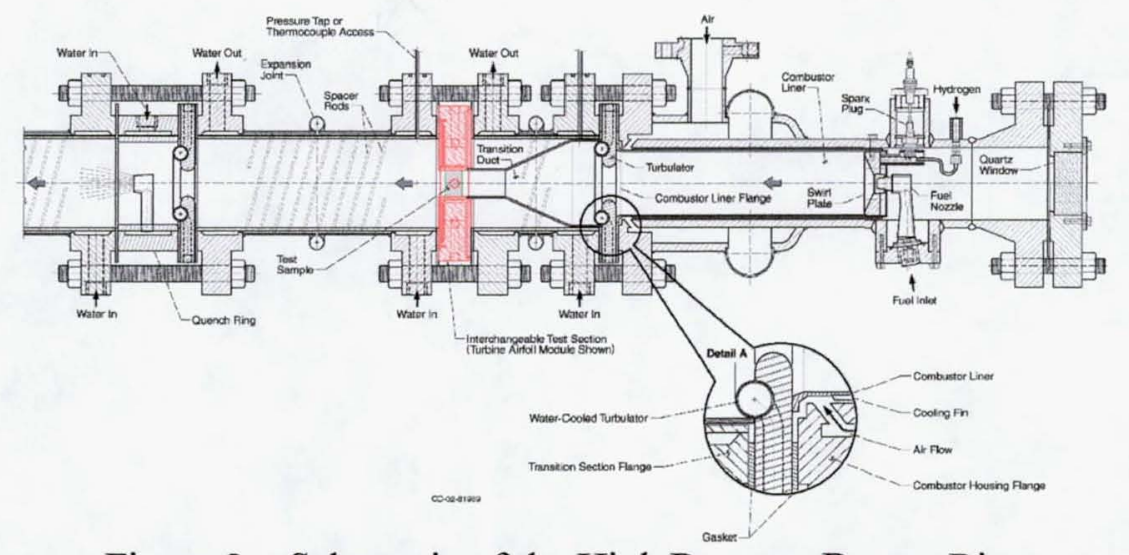

Figure 2 - Schematic of the High Pressure Burner Rig.

A water-cooled test module was designed fit into the existing flanges, tollow for separate gas and backside cooling paths, and providéaccess to ín surface and substrate temperaturestyusing optical and contact measurement techniques The hardware assembly for testing the Lean Transition Liners tesing is shown in Figure 39. The setup shows 4 set of $6^{5} \mathrm{LTL}^{x}$ attached to an impingement ring that recesses into the main water-cooled ring and is secured with a retaining cover plate. 'Cooling air is manifolded thry supply lines into the area behind the impingement ring that was machined to accommodate the Miller Attachments and distributed evenly onto the liners through holes in the impingement plate.

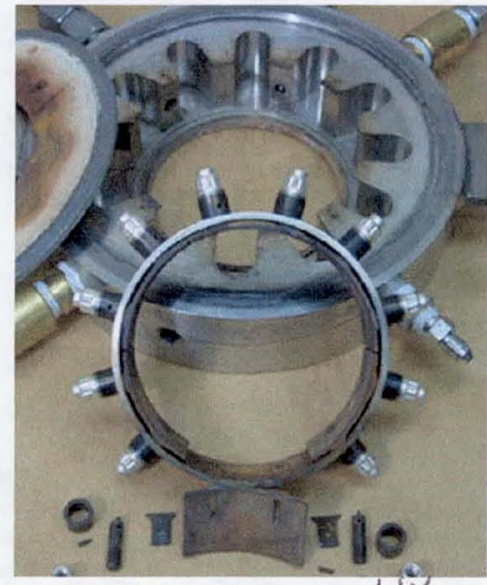

(a) $\operatorname{ass}$ embiy 2

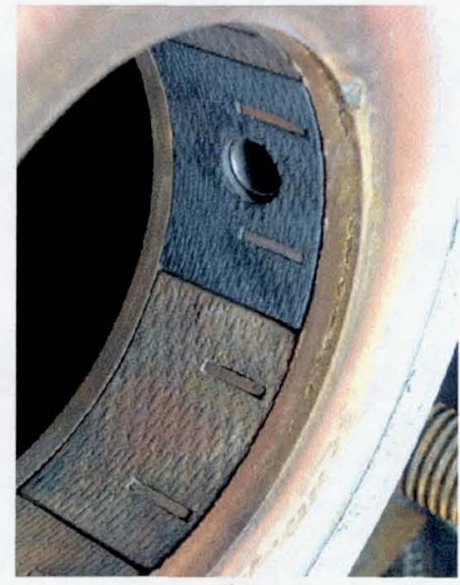

(b)

Figure 3 - Test setup a a 4 hes shows (a) assembly of parts including Miller attachments and (b) LTLs installed in test rig with pyrometer access port.

Testing was performed in phases to gather the different information to fully document the test. Initial intent was to the hardware, determine the backside cooling required to protect the impingement ring, and setur a baseline cycle. Calibration runs established adequate cooling flows, maintaining the metal 
temperatures typically below $400^{\circ} \mathrm{C}$ at maximum (stoichiometric) conditions. The cycle chosen was a 30 minute transient with 15 minutes of dwell time at 1425$1475^{\circ} \mathrm{C}$ gas temperature and gas velocities near $42 \mathrm{~m} / \mathrm{sec}$. Next, $1.3 \mathrm{~cm}$ hole was then added to the impingement ring to allow a 2-color optical pyrometer to monitor one LTL backside temperature, and a smaller $0.3 \mathrm{~cm}$ hole was used for a contact thermocouple measurement. Both thermocouple and pyrometer acknowledged that the substrate temperatures varied with cooling flow. For example, during the dwell time, the substrate temperature varied between $800^{\circ} \mathrm{C}$ and $915^{\circ} \mathrm{C}$ for the maximum and minimum cooling flows, respectively. A third configuration monitored the surface temperatures. For this, an additional $1.3 \mathrm{~cm}$ hole was added to the LTL positioned over the pyrometer port to allow viewing the hot side of the opposite LTL. This is configuration shown in Figure 3(b).

Finally, an additional fiber optic pyrometer was added to monitor the backside temperature and compare with the 2-color pyrometer. Calibrated for $\mathrm{SiC} / \mathrm{SiC}$ materials, the fiber optic consists if a sapphire tip directed perpendicular ( 90 degrees) to the LTL backside at a focal length of approximately $1 / 16_{\text {in }}^{\text {x }}$ using the $1 / 8_{\text {in }}$ diameter hole previously used for the contact thermocouple. The pyrometers displayed fairly good agreement over the entire range. Figure 4 illustrates the baseline cycle using data taken throughout the testing. The maximum fen surface $\left(925-985^{\circ} \mathrm{C}\right)$ and $\wedge^{\text {substrate }}\left(855-915^{\circ} \mathrm{C}\right)$ actures at $1425-1475^{\circ} \mathrm{C}$ gas temperatures, watiednesightly with backside cooling, as expected, and the gradient through the LTL remained essentially the same $\left(55-70^{\circ} \mathrm{C}\right)$.

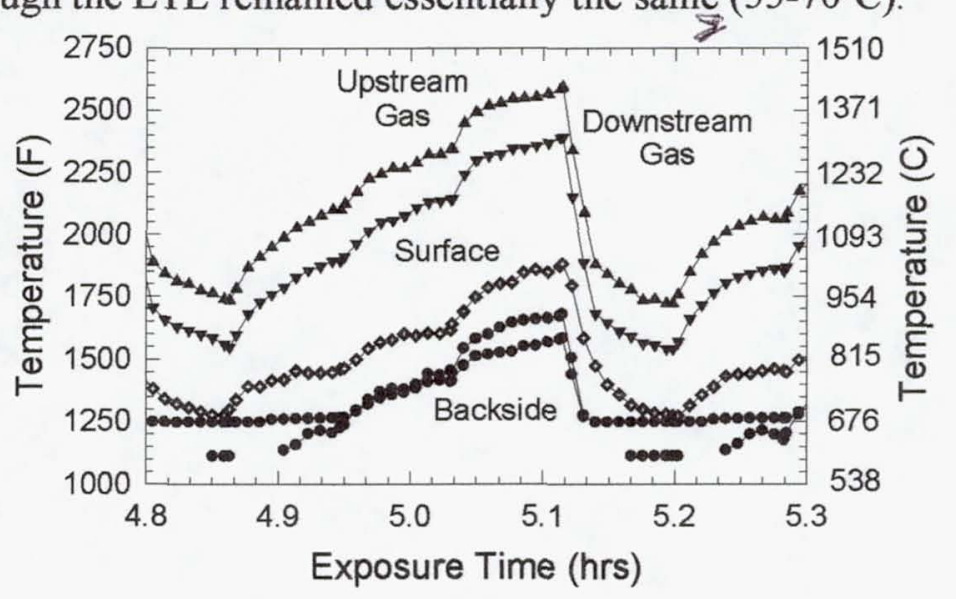

Figure 4 - Baseline HPBR cycle used to expose the LTLs.

\section{RESULTS AND DISCUSSION}

$$
\text { the testing }
$$

A total of $97.7 \mathrm{hrs}$ (174 cycles) were accumulated during initial torn on the original set of (6) LTLs and their attachments. Inspections at 5.7, 13.2, 44.7, and $97.7 \mathrm{hrs}$ indicating no visual signs of deterioration. Subsequent testing to acquire the substrate temperature data increased the exposures $/$ to 148.1 hours and 260 cycles, after which a significant amount of rust was noted on the LTLs. This was attributed to the service air that had contained some water during the time of the

$$
\begin{aligned}
& \text { entrained woter in the sewice air supply used } \\
& \text { for cooling. }
\end{aligned}
$$




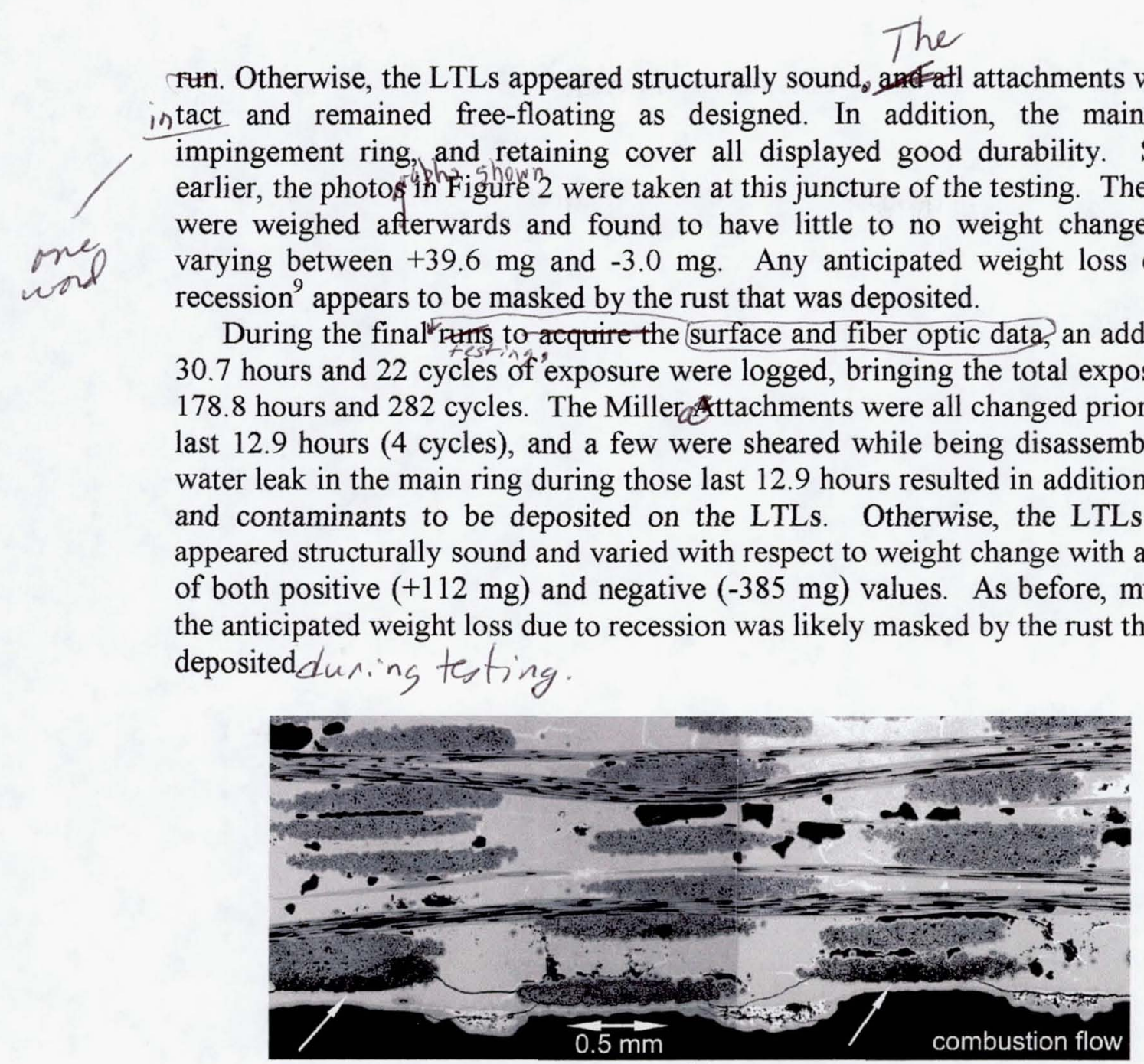

(a)

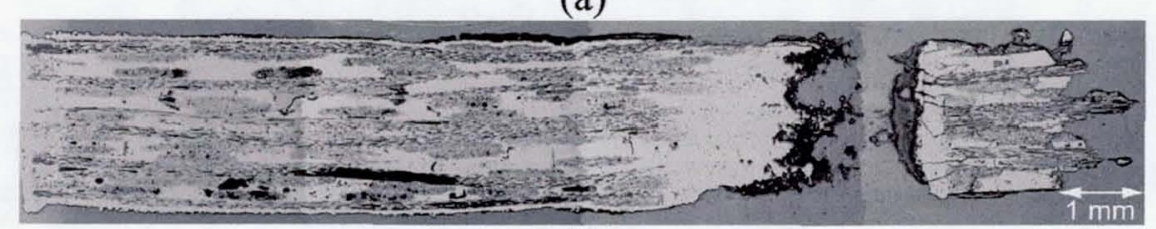

(b)

Figure 5 - Cross-sections of a) LTL and b) Miller attachment.

Figure 5 above shows the microstructure of the internal areas of one LTL and fastener after exposure. On the combustion side of the LTL in Figure 5(a), some fiber tows are either missing or depleted (as shown by arrows), and microcracking is seen throughout the matrix bridging the outermost individual fiber tows. This agrees well with damage found in the LTLs tested in the RQL Sector $\mathrm{Rig}$, as well as $\mathrm{SiC} / \mathrm{SiC}$ coupons tested in the High Pressure Burner Rig. In Figure had bea 
discontinuous to the left of that area. Here, the cross-section has been polished back near the sharp corner forming the "Y" (see Figure 1) where material was also degraded.

\section{CONCLUSIONS}

Testing of these Lean Transition Liners in the HPBR continues to provide invaluable experience and further the insight into the development of CMCs as gas turbine components. Like other work throughout industry to develop and test CMC turbine shrouds, combustor liners, and combustor cans $s_{s}^{1-3}$, these current configurations place such sub-element and component features in a realistic gas turbine environment under stressed conditions. Thus, an extremely economical test, as compared with full-scale engine testing, has been developed for reproducing $\mathrm{SiC}$ recession on a complex part and evaluating the structural integrity of component and fastener designs. This affords certain liberties to be taken with respect to higher risk configurations. In addition, ftestrang of EBC environmertal barner coat coated parts is planned not only on these segmented liners, buth a fully annular also been obtained and is being configured for testing.

\section{REFERENCES}

$$
\text { chemial vapor infiltrated }
$$

1. G. Corman, A. Dean, et. al, "Rig and Gas Turbine Testing of MI-CMC Combustor and Shroud Components", ASME paper 2001-GT-0593, 2001.

2. J. Shi, "Design, Analysis, Fabrication and Testing of a CMC Combustion Can", ASME paper 2000-GT-71, 2000.

3. N. Miriyala, J. Kimmel, J. Price, K. More, P. Tortorelli, H. Eaton, G. Linsey, and E. Sun, "The Evaluation of CFCC Liners after Field Testing in a Gas Turbine - III", ASME paper GT-2002-30585, 2002.

4. M.J. Verrilli and L.C. Martin, "RQL Sector Rig Testing of $\mathrm{SiC} / \mathrm{SiC}$ Combustor Liners", NASA/TM-2002-211509, April, 2002.

5. R.J. Miller, J.C. Moree, and D.C. Jarmon, "Design and Validation of High Temperature Composite Fasteners", proceedings of $39^{\text {th }}$ AIAA-ASMEASCE-AHS-ASC Structures, Structural Dynamics, and Materials Conference, Long Beach, CA, April 20-23, 1998, AIAA paper 98-1998.

6. D. Brewer, G. Ojard, and M. Gibler, "Ceramic Matrix Composite Combustor Liner Rig Test", ASME paper TE00CER03-03, May, 2000.

7. G. Ojard, R. Stephan, R. Naik, M. Gibler, R. Cairo, G. Linsey, J. Hornick, and D. Brewer, "NASA Rich Burn Quick Quench Lean Burn Sector Rig $\mathrm{SiC} / \mathrm{SiC}$ CMC Testing", in proceedings of $24^{\text {th }}$ Annual Conference on Composites, Materials, and Structures, Cocoa Beach, FL., Jan., 2000.

8. R.C. Robinson, "NASA GRC's High Pressure Burner Rig Facility and Materials Test Capabilities," NASA/CR-1999-209411, December 1999.

9. R.C. Robinson and J.L. Smialek, "SiC Recession Caused by $\mathrm{SiO} 2$ Scale Volatility under Combustor Conditions. Part I: Experimental Results and Empirical Model," J. Am. Ceram. Soc., 82 [7] 1817-25 (1999). 